\title{
The Chemical Photo catalysis in Food Safety
}

\author{
Jinying Chen ${ }^{1 *}$, YoujunJiang ${ }^{1}$, Yan Zhang ${ }^{2}$, Xiaozhe $\mathbf{Q i}^{2}$, Qiang Yuan ${ }^{2}$ \\ ${ }^{I}$ Sinograin Chengdu Storage Institute Co. Ltd., Chengdu, Sichuan, P.R. China \\ ${ }^{2}$ Standards and Quality Center of National Food and Strategic Reserves Administration, Beijing ,China \\ *Corresponding Author: Jinying Chen, Sinograin Chengdu Storage Institute Co. Ltd., Chengdu, \\ Sichuan, P.R. China
}

\begin{abstract}
Photocatalytic degradation is safe, non-toxic, and can be repeatedly catalyzed. It is a green degradation technology with broad application prospects. TiO2is the most extensive and in-depth study of semiconductor photocatalyst today. It's wide forbidden band $(3.2 \mathrm{eV})$ can only absorb ultraviolet light, and there are problems such as photo-generated electrons and holes are easy to recombine, and the amount of organic pollutants is small. One of the key factors that determines the kinetics of photocatalytic degradation, especially when the concentration of pollutants is in the ppm range, severely limits the application and development of photocatalytic technology in the environmental aspect.Photosensitization technology is a feasible way to improve $\mathrm{TiO}$ and catalyze organics in the visible light region.
\end{abstract}

Keywords: photocatalysis, green technology, mycotoxins, food safety

\section{INTRODUCTION}

\subsection{Research Significance and Purpose}

In the 21st century, one of the main goals of chemical research is to develop an efficient technology to replace energy-consuming processes that are harmful to the environment. This paper mainly describes the application of photocatalytic technology in food safety such as degradation of heavy metals, toxic substance, bacteria and mycotoxins. In photocatalytic organic synthesis, high selectivity of a target product can be achieved by optimizing the reaction environment, thus providing a green and energysaving way for organic synthesis, and becoming the most potential green organic chemistry technology in the 21st century.(Friedmann, Hakki, Kim, Choi, \& Bahnemann, 2016)

\subsection{Current Situation in Photocatalysis}

Hydrogen and oxygen, the prelude of photocatalytic technology was opened. The development of photocatalytic field instantly ignited the enthusiasm of researchers in this new field. With the development of research work, people's eyes are no longer confined to the system of photolysis of water to produce hydrogen, but to a broader world. In the past 40 years, the research reports on photocatalysissprang up like bamboo shoots after a spring rain. At present, most of the research work focuses on the environmental treatment(Yi et al., 2018) and improvement of degrading water as well as air pollutants(Dong et al., 2015), the conversion of solar energy and electrochemical processes such as interface electron transfer(Rangan, Arachchige, Brown, \& Brewer, 2009). Nevertheless, more and more attention has been paid to the application of photocatalysis in the synthesis of specific organic compounds. It is well known that traditional organic synthesis is not only cumbersome, but also uses some strong oxidants which are toxic or corrosive. The introduction of sunlight into organic synthesis system by photocatalytic reaction is undoubtedly a major breakthrough in terms of energy saving and environmental protection. The main reasons are as follows: (1) solar energy is a completely renewable resource; (2) the conditions required for photochemical excitation are much milder than those required for thermal catalysis; (3) photochemical excitation designs a shorter reaction history for people. 


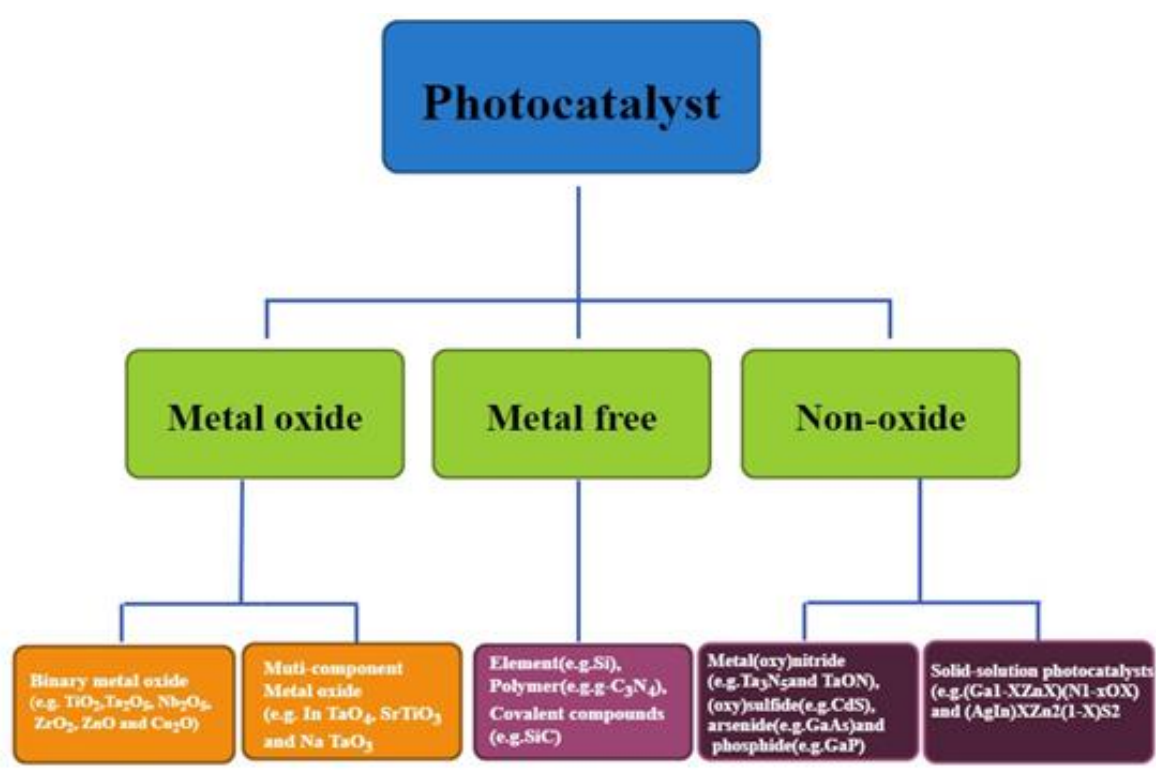

Figure1. Different kinds of Photo catalysts

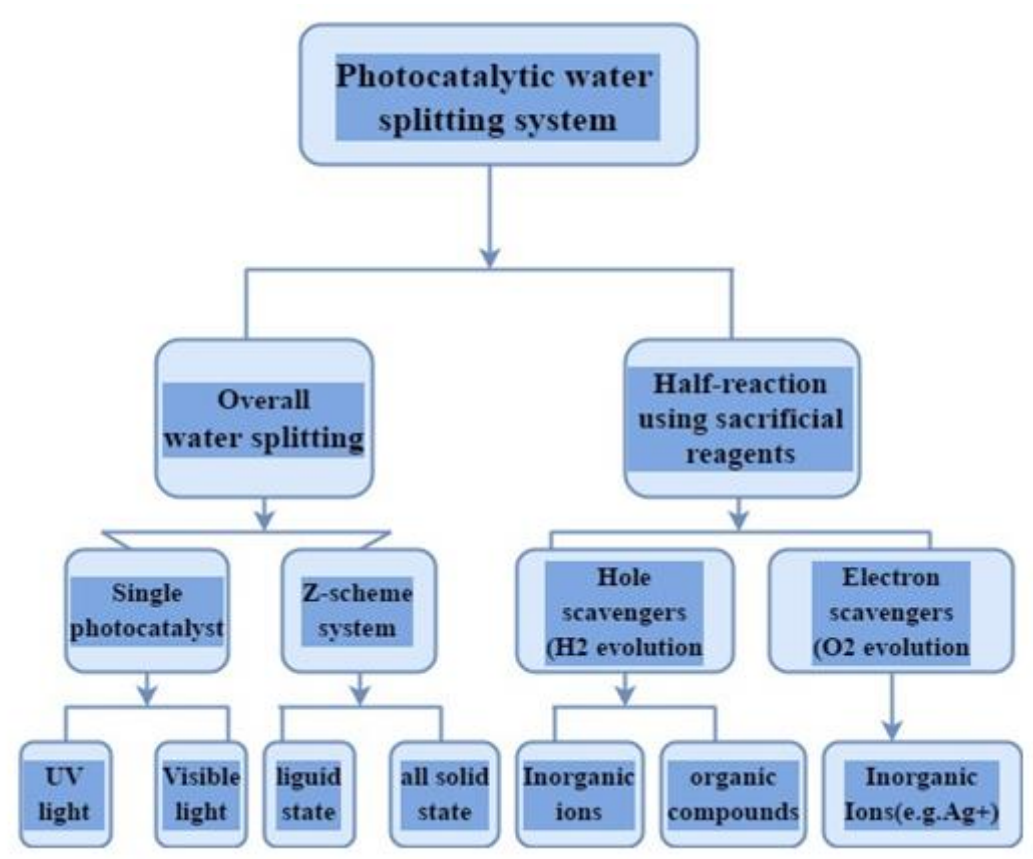

Figure2. Different systems for photo catalytic water splitting

\section{Materials AND Methods}

\subsection{Photo catalysis in Antimicrobial Effect}

Karantonis(Karantonis, Koutsaftis, \& Kouloumbi, 2006)thinks main materials of photocatalytic antimicrobial agents are n-type semiconductors, such as titanium dioxide, zinc oxide, CdS, WO3, $\mathrm{SnO} 2, \mathrm{ZrO}$, etc. According to the principles to be followed in selecting antimicrobial agents: safety, non-toxicity, biocompatibility, high activity, wide range of sterilization, small odor, good stability, low price, wide source, etc. Among these semiconductors, titanium dioxide, Cds and zinc oxide have the highest catalytic activities. However, zinc oxide is unstable in water, which will generate $\mathrm{Zn}(\mathrm{OH})$ 2 on the surface of particles, which will affect the antimicrobial effect. CdS is also unstable when it is irradiated by light, which can cause cathodic photocorrosion and produces $\mathrm{Cd} 2$ ions that are toxic to organisms and harmful to the environment. And nano-titanium dioxide accords with the above principles. At the same time, the antimicrobial effect of nano-titanium dioxide is exerted through photocatalysis, which will not decrease the antimicrobial effect as other antimicrobial agents gradually consume with the use of antimicrobial agents. Experiments show that nano-titanium dioxide has strong killing ability to Pseudomonas aeruginosa, Escherichia coli, Staphylococcus aureus, 
Salmonella, Bacillus and Aspergillus. Based on the excellent properties of nano-titanium dioxide, it is the most commonly used photocatalytic antimicrobial agent.

Wang Xiaoyan(Xiaoyan, Huixiang, \& Shaoli, 2010) (2014) found that the antimicrobial mechanism is that the catalyst is irradiated by light and absorbs light energy. If the energy of photons is higher than the band gap of semiconductors, the valence band electrons of semiconductors transit from valence band to conduction band, forming "electron-hole" pairs, and directly redox the bacteria adsorbed on the surface.

Khalil L(Khalil, Mourad, \& Rophael, 1998) (2008) found that the self-cleaning and anti-bacterial effects of the catheter surface were greatly enhanced by coating a layer of photocatalytic material film based on titanium dioxide on the catheter surface. It was also found that the adherent bacteria could be killed when light was introduced into the catheter by optical fibers. And then, KI-TiO2, KIO4-TiO2, I2-TiO2, HI-TiO2 and blank control showed that KI-TiO2, KIO4-TiO2, I2-TiO2 and $\mathrm{HI}-\mathrm{TiO} 2$ had certain degradation effects on $\mathrm{RhB}$ under visible light, and the activity of catalyst was higher than that of pure titanium dioxide. It was also found that when prepared by the same method, KI-titanium dioxide had the most obvious degradation effect on RhB. After 60 minutes of illumination, the degradation rate of $\mathrm{RhB}$ reached $62 \%$. At present, most researchers believe that the photocatalytic activity of catalysts is inseparable from the active species produced under light. Hydroxyl and superoxide groups play a key role in many photocatalytic reactions, such as the degradation of organic pollutants, photocatalytic and antimicrobial systems.

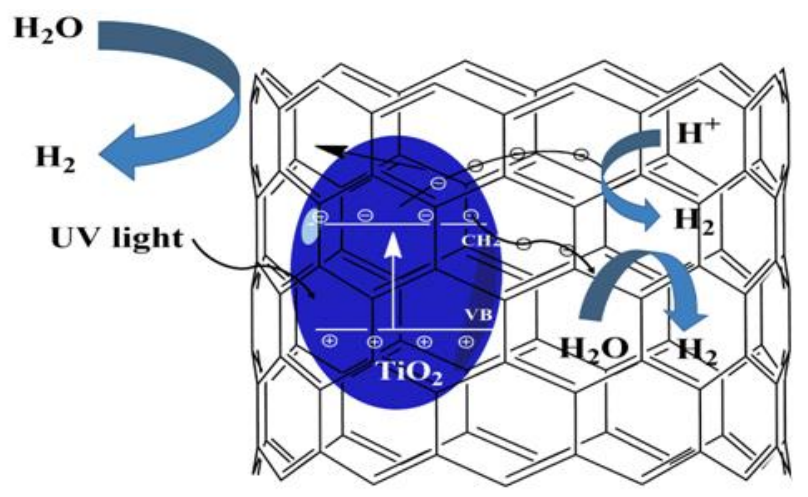

Figure3. Photocatalysis capacity of nano-titaniumdioxide

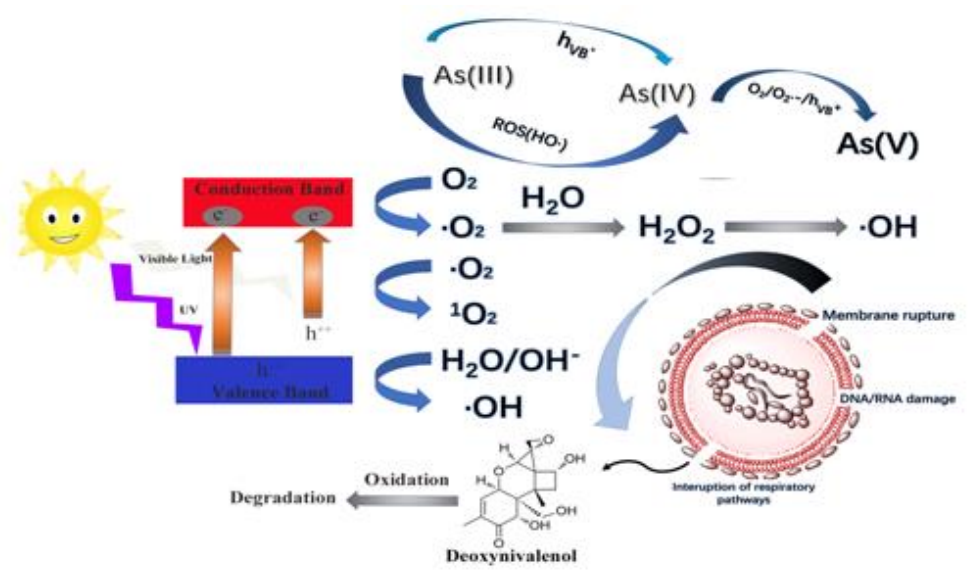

Figure4. Photocatalysis procedures in mycotoxin and bacterial degradation

\subsection{Photocatalysis in Heavy Metal Degradation}

Arsenic, Cadmium, Lead and Mercury are classified as the carcinogenic elements of Group I. Severe health effects have been observed in chronicallyexposed populations worldwide that consume water contaminatedwith these compounds. In the study of B. L. Rivas's research(Yuksel et al., 2014), the photocatalytic oxidation of hazardous arsenite $(\mathrm{As}(\mathrm{III}))$ to arsenate $(\mathrm{As}(\mathrm{V}))$ and the sequential removalof arsenate from aqueous solution by liquid-phase polymer-based retention (LPR) were investigated. The photocatalytic oxidation ofarsenite was performed using TiO2 (P25 Degussa, Germany) under UV-A light. 
Cappelletti et al. (Cappelletti, Bianchi, \& Ardizzone, 2008)(2008), using nanocrystalline TiO2 samples and differentsacrificial molecules (formic acid, isopropyl alcohol and sodium sulfite),found $\mathrm{Cr}(0)$ formation at the $\mathrm{TiO} 2$ surface. Since the reduction potentialfor $\mathrm{Cr}(\mathrm{III})$ to $\mathrm{Cr}(\mathrm{II})$ is $\_0.42 \mathrm{~V}$ and the global reduction potential fromCr(III) to $\mathrm{Cr}(0)$ is _ $0.74 \mathrm{~V}$ (Bard, Parsons, \& Jordan, 1985) (Bard et al., 1985).Mercury transformation by heterogeneous photocatalysis with semiconductors(including electrodes, micro- and nanoparticles) such as $\mathrm{ZnO}$, TiO2,WO3 under $\mathrm{UV}$, visible irradiation, and even solar light has been reported ina series of papers. It was concluded that the removal efficiency depends strongly on $\mathrm{pH}$,that the reaction is inhibited by oxygen and that there is an enhancement byorganic donors. Recent results of our group (Murruni et al., 2007, 2008)(Murruni, Conde, Leyva, \& Litter, 2008; Murruni, Leyva, \& Litter, 2007) using TiO2 andPt_TiO2 under different conditions tried to shed light on the mechanismsrelated to this complex system. As in previous reported cases, a low $\mathrm{Pb}$ (II) removal was obtained over pure $\mathrm{TiO} 2$ either in theabsence or in the presence of oxygen.

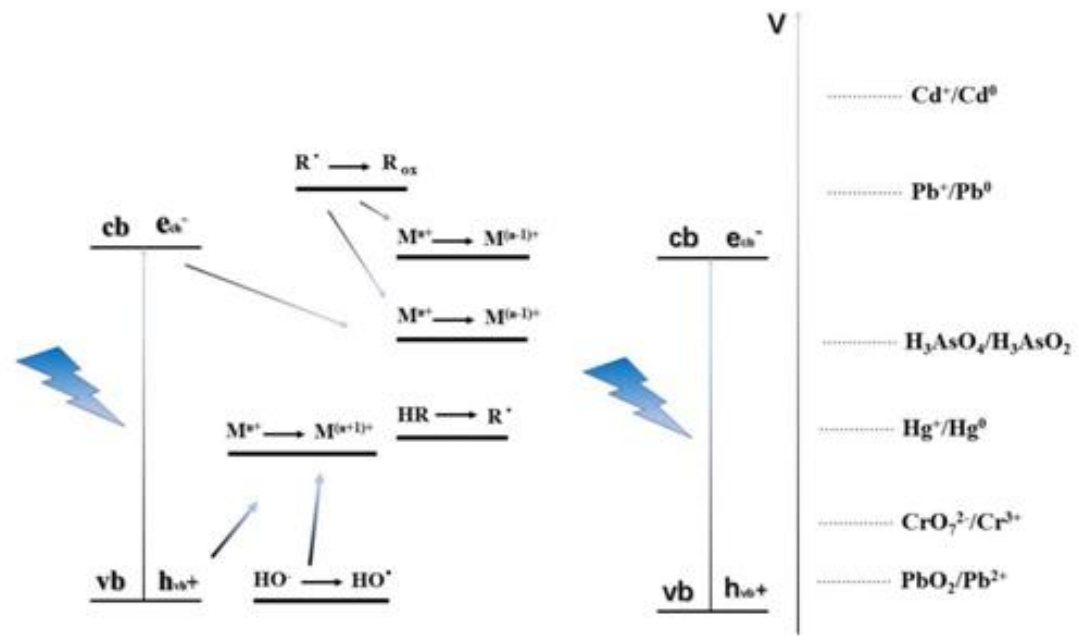

Figure4. Heavy metal reaction by photocatalysis

\subsection{Photocatalysis in Conversion of Benzene to Phenol}

At present, the research on the biodegradation of mycotoxins is becoming a hotspot at home and abroad. The hydroxylation of mycotoxins is particularly important in chemical industry. Among many photocatalytic oxidation reactions of aromatic compounds, the conversion of benzene to phenol is one of the most important reactions, because phenol is widely used, such as a disinfectant, precursor of phenolic resin, reagent in chemical analysis and preservative of dispensing drugs. Many studies (Park \& Choi, 2005; G. Zhang, Yi, Shim, Lee, \& Choi, 2011)have shown that benzene can be selectively oxidized to phenol in the system of titanium dioxide. In the direct conversion of benzene to phenol, the electrophilic radicals and hydroxyl radicals on the surface of titanium dioxide are added directly to the benzene ring to produce phenol by hydroxylation. However, the hydroxyl radicals have very strong oxidation ability, so they can further decompose the phenol which has been produced, resulting in the low selectivity of the reaction to phenol. Chen et al. (Chen, Eberlein, \& Langford, 2002)found that titanium dioxide loaded on ZSM-5 zeolite had better yield and selectivity for phenol. The results showed that when the conversion of benzene was $70 \%$, the yield and selectivity of phenol were $15 \%$ and $21 \%$, respectively. Because phenol had lower affinity to the surface of photocatalyst than benzene, the hydroxylation of benzene was catalyzed. It can be seen that the relative affinity of reactants and products on the surface of catalysts will directly affect the selectivity of the reaction system, which provides a method and basis for improving the selectivity of the system to a certain target product.

Park and Choi(Park et al., 2005)studied the effects of various parameters (surface modification of electron acceptors and combined use of photocatalysts) on the direct production of phenol by photocatalytic selective oxidation of benzene. They found that the addition of $\mathrm{Fe} 3+, \mathrm{H} 2 \mathrm{O} 2$ or $\mathrm{Fe} 3+$, such as electron acceptors, in the suspension of titanium dioxide could significantly improve the yield and selectivity of phenol. In addition, surface modification of titanium dioxide by noble metal loading or fluorination was also carried out. The combination of titanium dioxide and polyoxometalate (POM) also improved the yield and selectivity of phenol. Most notably, the yield of phenol increased from $2.6 \%$ to $11 \%$ after POM was added to the suspension of titanium dioxide. 


\subsection{Photocatalysis Incyclization}

Photocatalytic technology has been applied tocyclization of amino acidswith its unique properties. Similarly, with semiconductor photocatalysts, the cyclization of amino acids is not carried out independently as in the conventional photocatalytic oxidation-reduction reaction. In the process of cyclization of amino acids, the reactants are oxidized first, then reduced to form cyclic amino acids. The products contain two structures, one retains the original chirality and the other loses chirality. A series of processes have aroused great interest. Otani B(Ohtani, Pal, \& Ikeda, 2003)and others have made a detailed review of the selective cyclization of amino acids. Primary amine can be converted to imine by photocatalytic oxidation-reduction reaction. Primary amine is oxidized to demoniac to form aldehyde, aldehyde and primary amine are dehydrated to form carbon-nitrogen double bond, and then reduced to imine.

\subsection{Photocatalysis in Alcohol Oxidation}

Zhao Jincai's(M. Zhang, Chen, Ma, \& Zhao, 2008)groupdesigned a very ingenious dye-titanium dioxide-TEMPO ternary combination system, and used this system to test the photocatalytic selectiveoxidation of a series of alcoholsunder aerobic conditions. In this system, dye alizarin red (AR) as a sensitizer absorbs light energy, which not only extends the response range of light to the visible region, but also avoids the system. The formation of moderately strong oxidative holes and hydroxyl radicals. As an electron acceptor, TEMPO + can effectively selectively oxidize a series of aromatic alcohols and aliphatic alcohols to produce corresponding aldehydes. They also made corresponding amplification experiments on benzyl alcohol and obtained high selectivity. Later, the team also studied the photocurrent effect of titanium dioxide by using oxygen isotope method. The transfer process of oxygen atoms in alcohols by chemical selective oxidation is a pioneering exploration of the mechanism of photocatalytic selective oxidation of alcohols.

\subsection{Photocatalysis in Carbonylation}

Carbonylation is the most commonly used method in organic synthesis and occupies a very important position in industrial production. Conventional carbonylation reaction mostly requires high temperature and high pressure, precious metal catalyst is needed, and the reaction is difficult to control, many side reactions and other adverse factors; while photocatalytic reaction is usually carried out under normal temperature and pressure, which is easy to control and no secondary pollution. Therefore, photocatalytic technology is naturally introduced into carbonylation, such as the reaction of carbon monoxide (or carbon dioxide) with halogenated hydrocarbons, olefins, ketones and aromatic compounds. Aryl halo hydrocarbons can be converted into corresponding carboxylic acid salts by phase transfer catalysts under illumination. The reaction takes place at atmospheric pressure. The light source has a great influence on the reaction. Carbonylation of primary, secondary and tertiary diazohydrocarbons can also occur under light, while Bromo hydrocarbons and chlorinated hydrocarbons are difficult to occur under the same conditions. Carbon monoxide was the main source of carbonyl carbon in the initial study of photocatalytic carbonylation of olefins. Inoue S(Komatsu, Aida, \& Inoue, 1991)studied a series of photocatalytic reactions of carbon dioxide with alpha, beta unsaturated esters and cyanide using porphyrin aluminum as catalyst. The results show that porphyrin aluminum reacts with unsaturated esters of alpha and beta at first, then carbon dioxide is inserted into the intermediate to form aluminum carboxylate, and acid is formed under acidic conditions. Diethyl zinc can make the catalyst regenerate continuously. Carbon dioxide is carbonylated with ketone to form beta-carboxylic acid under light conditions using porphyrin aluminum as photocatalyst. The reaction passes through the transition state of enol complex, which is used as nucleophilic reagent to attack carbon dioxide to produce beta-ketoacid aluminum, which is converted to diketone under acidic conditions. In the reaction, the addition of methyl ornidazole is very important, because it can coordinate on the vacancy of porphyrin aluminum, forcing the $\mathrm{N} 4 \mathrm{Al}$ skeleton to be planar, which greatly improves the activity of enol complexes.

\section{Prospect}

Photocatalytic antimicrobial technology is a green disinfection and sterilization technology, because it can not only effectively kill bacteria and other microorganisms, but also degrade endotoxin produced by bacteria. ChamornChawengkijwanich and Yasuyoshi Hayata(2015)(Chawengkijwanich\& Hayata, 2008)developed the food packaging film of titanium dioxide. In the test tube and actual test, it was 
found that the food packaging film of titanium dioxide can reduce microbial contaminants on the surface of solid food and reduce the new food. The risk of microbial contamination of fresh cut noodles.

Mycotoxins are a kind of secondary metabolites produced by toxic fungi in the process of hazards(Mateo, Mateo, Hinojo, Llorens, \& Jiménez, 2002). They mainly include aflatoxin(Williams \& Windham, 2001), deoxynivalenol (DON)(Manoharan et al., 2006), zearalenone (ZEN), fumonisin (FUM) (Duvick, 2001)and ochratoxin(Kononenko, Burkin, Zotova, \& Soboleva, 2000). In recent years, the frequent occurrence of extreme climate in China has led to a major outbreak of scab, which mainly harms wheat and maize. In order to ensure the safety of people's consumption and animal husbandry in China, the State Food Administration and relevant departments of China infected seriously with scab during the wheat harvest season in the Huanghuai-Haihai region in 2010. Large areas of DON-exceeding toxin-exceeding wheat were sealed up in time, totaling 174.5 million tons. Due to the lack of effective security processing technology, it is still in the state of storage. The Wheat Scab Epidemic in 2012 resulted in the excess of DON and ZEN toxins in Wheat in Anhui, Jiangsu and Henan provinces. Studying the safe utilization of toxin-exceeding grain can not only protect the interests of farmers in China, but also prevent the flow into grain market to safeguard the quality and safety of national grain and food. For the removal of mycotoxins, physical removal, adsorption and chemical treatment are the most common methods at home and abroad. Adsorbents adsorb mycotoxins and also adsorb a large number of micronutrients in feed and food. Toxins adsorbed by clay can not be decomposed, which will cause secondary pollution. Photodegradation not only can efficiently convert toxins into non-toxic products, environmental protection and safety, but also has strong specificity and high conversion efficiency. It has become the most promising treatment technology in the current mycotoxin reduction technology(Bai et al., 2017). It is not only safe, environmentally friendly and efficient, but also in line with the current development trend of energy saving and emission reduction in China by using modern biotechnology.

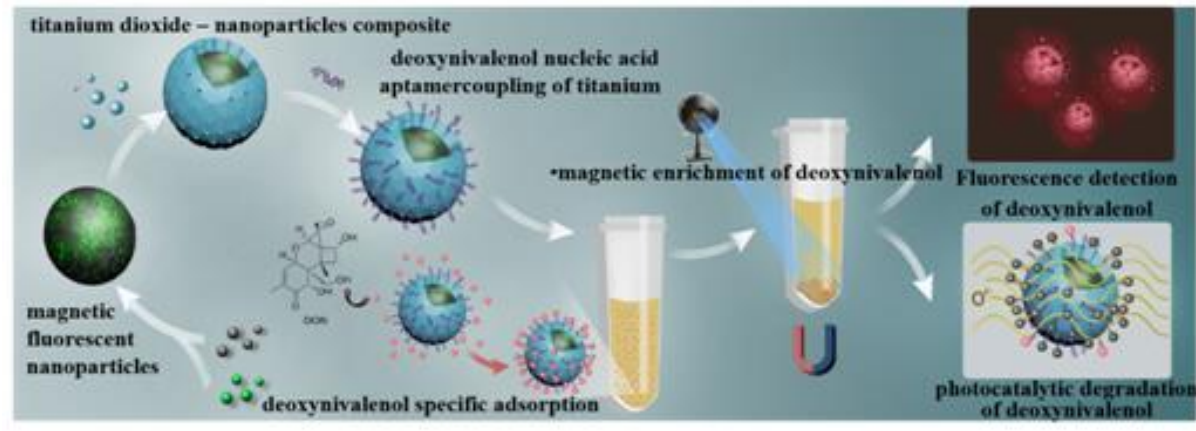

Figure5. New magnetic fluorescent nanoparticles for deoxynivalenol detection and degradation

D. Koutsaftis(Singh, Mahalingam, \& Singh, 2013)think titanium dioxide nano-film can be well attached to the surface of ceramics, glass, plastics and other materials. After being stimulated by light, it can effectively remove pollutants and sterilize in the environment, and inhibit cancer cells. The commonly used load methods include slurry sizing, gluing, sol-gel, liquid phase deposition, chemical vapor deposition (CVD) and physical vapor deposition (PVD). However, the liquid phase deposition method is simple to operate and does not require complex, precious and precise instruments, and does not require high temperature calcination treatment.

Photocatalytic technology also faces a series of challenges. First of all, the solar energy utilization rate is low and the quantum efficiency is not high. For example, anatase phase titanium dioxide can only be excited by ultraviolet light, and can not deal with a large number of industrial waste liquids. Secondly, the mechanism is not very clear. Its theoretical basis is the energy band theory of physics. At present, the photocatalytic theory based on it can not explain many experimental phenomena. For example, some amorphous and insulator photocatalysts have good photocatalytic effect, but some semiconductor materials with good photoelectric response do not have good photocatalytic activity. Finally, although the powder catalyst can be well dispersed in the reaction system, it is difficult to recover. In addition, nano-titanium dioxide on the surface of some materials needs high-temperature sintering to obtain better activity, while many disposable medical consumables are plastic and can not withstand high temperature. Therefore, the preparation of nano-titanium dioxide antimicrobial film at low temperature will be another direction of nano-titanium dioxide research in the future. 


\section{CONCLUSION}

China's total grain output is growing slowly, while the demand for grain is increasing. The prevention and control of mycotoxin pollution is one of the effective ways to alleviate the shortage of food resources. Due to the frequent occurrence of extreme climate in China, food poisoning and mycotoxin pollution have increased year by year. In order to ensure the safety of consumption, the state has sealed up the grain and oil products with mycotoxin exceeding the standard. At present, it is urgent to study effective treatment technologies and strategies. Firstly, we should improve the limit standards and regulations of mycotoxins in grain to ensure food safety and protect consumers 'health; secondly, we should establish a national awareness of prevention and control and reduction of mycotoxins; lastly, for contaminated grain, we should carry out research on the treatment technology of mycotoxin pollution reduction in grain storage, and use the efficient degradation of microorganisms to convert toxins into non-toxic products, and ultimately to grain. Reduction of mycotoxins in food provides safe, green and environmentally friendly technical support.

\section{ACKNOWLEDGMENT}

The authors would like to thank "Young Elite Scientists Sponsorship Program by CAST, YESS, 2018QNRC001"

\section{REFERENCES}

[1] Bai, X., Sun, C., Liu, D., Luo, X., Li, D., Wang, J. . . Zhu, Y. (2017). Photocatalytic degradation of deoxynivalenol using graphene/ZnO hybrids in aqueous suspension. Applied Catalysis B: Environmental, 204, 11-20. https://doi.org/https://doi.org/10.1016/j.apcatb.2016.11.010.

[2] Bard, A. J., Parsons, R., \& Jordan, J. (1985). Standard Potentials in Aqueous Solution.

[3] Cappelletti, G., Bianchi, C. L., \& Ardizzone, S. (2008). Nano-titania assisted photoreduction of $\mathrm{Cr}(\mathrm{VI})$ : The role of the different $\mathrm{TiO} 2$ polymorphs. Applied Catalysis B: Environmental, 78(3), 193-201. https://doi.org/https://doi.org/10.1016/j.apcatb.2007.09.022.

[4] Chawengkijwanich, C., \& Hayata, Y. (2008). Development of TiO2 powder-coated food packaging film and its ability to inactivate Escherichia coli in vitro and in actual tests. International journal of food microbiology, 123 3, 288-292.

[5] Chen, J., Eberlein, L., \& Langford, C. H. (2002). Pathways of phenol and benzene photooxidation using TiO2 supported on a zeolite. Journal of Photochemistry and Photobiology A: Chemistry, 148(1), 183-189. https://doi.org/https://doi.org/10.1016/S1010-6030(02)00041-2.

[6] Dong, S., Feng, J., Fan, M., Pi, Y., Hu, L., Han, X. . . . Sun, J. (2015). Recent developments in heterogeneous photocatalytic water treatment using visible light-responsive photocatalysts: a review. RSC Advances, 5(19), 14610-14630. https://doi.org/10.1039/C4RA13734E.

[7] Duvick, J. (2001). Prospects for reducing fumonisin contamination of maize through genetic modification. Environmental Health Perspectives, 109(suppl 2), 337-342. https://doi.org/10.1289/ehp.01109s2337.

[8] Friedmann, D., Hakki, A., Kim, H., Choi, W., \& Bahnemann, D. (2016). Heterogeneous photocatalytic organic synthesis: state-of-the-art and future perspectives. Green Chemistry, 18(20), 5391-5411. https://doi.org/10.1039/C6GC01582D.

[9] Karantonis, A., Koutsaftis, D., \& Kouloumbi, N. (2006). Bistability, oscillations and bifurcations of the electrocatalytic oxidation of $\mathrm{HCHO}$ on Pt. Chemical Physics Letters, 422(1), 78-82. https://doi.org/https://doi.org/10.1016/j.cplett.2006.02.033.

[10] Khalil, L. B., Mourad, W. E., \& Rophael, M. W. (1998). Photocatalytic reduction of environmental pollutant $\mathrm{Cr}(\mathrm{VI})$ over some semiconductors under UV/visible light illumination. Applied Catalysis B: Environmental, 17(3), 267-273. https://doi.org/https://doi.org/10.1016/S0926-3373(98)00020-4.

[11] Komatsu, M., Aida, T., \& Inoue, S. (1991). Novel visible-light-driven catalytic carbon dioxide fixation. Synthesis of malonic acid derivatives from $\mathrm{CO} 2$, an alpha.,.beta.-unsaturated ester or nitrile, and diethylzinc catalyzed by aluminum porphyrins. Journal of the American Chemical Society, 113(22), 84928498. https://doi.org/10.1021/ja00022a042.

[12] Kononenko, G. P., Burkin, A. A., Zotova, E. V., \& Soboleva, N. A. (2000). Ochratoxin A: Contamination of grain. Applied Biochemistry and Microbiology, 36(2), 177-180. https://doi.org/10.1007/BF02737916.

[13] Manoharan, M., Dahleen, L. S., Hohn, T. M., Neate, S. M., Yu, X.-H., Alexander, N. J., . . Horsley, R. D. (2006). Expression of 3-OH trichothecene acetyltransferase in barley (Hordeum vulgare L.) and effects on $\begin{array}{llll}\text { deoxynivalenol. } & \text { Plant } & \text { Science, } & \text { 171(6), }\end{array}$ https://doi.org/https://doi.org/10.1016/j.plantsci.2006.07.004. 
[14] Mateo, J. J., Mateo, R., Hinojo, M. J., Llorens, A., \& Jiménez, M. (2002). Liquid chromatographic determination of toxigenic secondary metabolites produced by Fusarium strains. Journal of Chromatography A, 955(2), 245-256. https://doi.org/https://doi.org/10.1016/S0021-9673(02)00214-5.

[15] Murruni, L., Conde, F., Leyva, G., \& Litter, M. I. (2008). Photocatalytic reduction of Pb(II) over TiO2: New insights on the effect of different electron donors. Applied Catalysis B: Environmental, 84(3), 563569. https://doi.org/https://doi.org/10.1016/j.apcatb.2008.05.012.

[16] Murruni, L., Leyva, G., \& Litter, M. I. (2007). Photocatalytic removal of Pb(II) over TiO2 and Pt? $\square \mathrm{TiO} 2$ powders. Catalysis Today, 129(1), 127-135. https://doi.org/https://doi.org/10.1016/j.cattod.2007.06.058.

[17] Ohtani, B., Pal, B., \& Ikeda, S. (2003). Photocatalytic Organic Syntheses: Selective Cyclization of Amino Acids in Aqueous Suspensions. Catalysis Surveys from Asia, 7(2), 165-176. https://doi.org/10.1023/A:1025389725637.

[18] Park, H., \& Choi, W. (2005). Photocatalytic conversion of benzene to phenol using modified TiO2 and $\begin{array}{llll}\text { polyoxometalates. } & \text { Catalysis } & \text { Today, } & \text { 101(3), }\end{array}$ https://doi.org/https://doi.org/10.1016/j.cattod.2005.03.014.

[19] Rangan, K., Arachchige, S. M., Brown, J. R., \& Brewer, K. J. (2009). Solar energy conversion using photochemical molecular devices: photocatalytic hydrogen production from water using mixed-metal supramolecular complexes. Energy \& Environmental Science, 2(4), 410-419. https://doi.org/10.1039/B812049H.

[20] Singh, S., Mahalingam, H., \& Singh, P. K. (2013). Polymer-supported titanium dioxide photocatalysts for environmental remediation: A review. Applied Catalysis A: General, 462-463, 178-195. https://doi.org/https://doi.org/10.1016/j.apcata.2013.04.039.

[21] Williams, W. P., \& Windham, G. L. (2001). Registration of Maize Germplasm Line Mp715. Crop Science, 41(4), 1374-1375. https://doi.org/10.2135/cropsci2001.4141374-ax.

[22] Xiaoyan, W., Huixiang, W., \& Shaoli, W. (2010). Ambient formaldehyde and its contributing factor to ozone and $\mathrm{OH}$ radical in a rural area. Atmospheric Environment, 44(17), 2074-2078. https://doi.org/https://doi.org/10.1016/j.atmosenv.2010.03.023.

[23] Yi, H., Huang, D., Qin, L., Zeng, G., Lai, C., Cheng, M. . . Guo, X. (2018). Selective prepared carbon nano materials for advanced photo catalytic application in environmental pollutant treatment and hydrogen $\begin{array}{llllll}\text { production. } & \text { Applied } & \text { Catalysis } & \text { B: } & \text { Environmental, } & \text { 239, }\end{array}$ https://doi.org/https://doi.org/10.1016/j.apcatb.2018.07.068.

[24] Yuksel, S., Rivas, B. L., Sánchez, J., Mansilla, H. D., Yañez, J., Kochifas, P., . . . Bryjak, M. (2014). Water-soluble polymer and photocatalysis for arsenic removal. Journal of Applied Polymer Science, 131(19). https://doi.org/10.1002/app.40871.

[25] Zhang, G., Yi, J., Shim, J., Lee, J., \& Choi, W. (2011). Photocatalytic hydroxylation of benzene to phenol over titanium oxide entrapped into hydrophobically modified siliceous foam. Applied Catalysis B: Environmental, 102(1), 132-139. https://doi.org/https://doi.org/10.1016/j.apcatb.2010.11.034.

[26] Zhang, M., Chen, C., Ma, W., \& Zhao, J. (2008). Visible-Light-Induced Aerobic Oxidation of Alcohols in a Coupled Photocatalytic System of Dye-Sensitized TiO2 and TEMPO. Angewandte Chemie International Edition, 47(50), 9730-9733. https://doi.org/10.1002/anie.200803630.

Citation: Jinying Chen, et.al, "The Chemical Photo catalysis in Food Safety”, International Journal of Research Studies in Biosciences, 8(4), pp. 8-15. DOI: http://dx.doi.org/10.20431/2349-0365.0804002

Copyright: (c) 2020 Authors, This is an open-access article distributed under the terms of the Creative Commons Attribution License, which permits unrestricted use, distribution, and reproduction in any medium, provided the original author and source are credited. 